\title{
Cellular Photo Digital Breathalyzer for Monitoring Alcohol Use: A Pilot Study
}

\author{
Gregory E. Skipper ${ }^{\mathrm{a}}$ Natasha Thon ${ }^{\mathrm{c}}$ Robert L. DuPont ${ }^{\mathrm{b}}$ Michael D. Campbell ${ }^{\mathrm{b}}$ \\ Wolfgang Weinmann ${ }^{d}$ Friedrich M. Wurst ${ }^{c}$ \\ a Promises Treatment Centers, Los Angeles, Calif., and ${ }^{\mathrm{b}}$ Institute for Behavior and Health, Rockville, Md., USA; \\ 'Department of Psychiatry and Psychotherapy II, Christian Doppler Hospital, Paracelsus Medical University, \\ Salzburg, Austria; ${ }^{d}$ Institute of Forensic Medicine, University of Bern, Bern, Switzerland
}

\author{
Key Words \\ Breathalyzer · Ethyl glucuronide · Alcohol monitoring · \\ Biomarkers · Self-reports
}

\begin{abstract}
Background: Monitoring alcohol use is important in numerous situations. Direct ethanol metabolites, such as ethyl glucuronide (EtG), have been shown to be useful tools in detecting alcohol use and documenting abstinence. For very frequent or continuous control of abstinence, they lack practicability. Therefore, devices measuring ethanol itself might be of interest. This pilot study aims at elucidating the usability and accuracy of the cellular photo digital breathalyzer (CPDB) compared to self-reports in a naturalistic setting. Method: 12 social drinkers were included. Subjects used a CPDB 4 times daily, kept diaries of alcohol use and submitted urine for EtG testing over a period of 5 weeks. Results: In total, the 12 subjects reported 84 drinking episodes. 1,609 breath tests were performed and 55 urine EtG tests were collected. Of 84 drinking episodes, CPDB detected $98.8 \%$. The compliance rate for breath testing was $96 \%$. Of the $55 \mathrm{EtG}$ tests submitted, $1(1.8 \%)$ was positive. Conclusions: The data suggest that the CPDB device holds promise in detecting high, moderate, and low alcohol intake. It seems to have advantages compared to biomarkers and other monitoring
\end{abstract}

devices. The preference for CPDB by the participants might explain the high compliance. Further studies including comparison with biomarkers and transdermal devices are needed.

(c) 2013 S. Karger AG, Basel

\section{Introduction}

Alcohol monitoring to document abstinence is conducted in numerous settings including treatment and recovery from alcohol or other substance addiction, courtordered abstinence, custody cases in which child visitation is contingent upon parental abstinence, regulatory board or professional monitoring programs mandating abstinence as a condition of licensure or return to work, family or school monitoring of alcohol consumption in children, and in medical clinics when alcohol use may cause exacerbation of underlying medical problems (e.g. diabetes, esophagitis, or liver transplantation). Alcohol monitoring in these settings is useful for advocacy, deterrence, and early detection of relapse [1].

The value of monitoring alcohol use by measuring its presence in blood, breath, or urine is limited since alcohol itself remains detectable in the body for a period of hours only. Residual biomarkers can, however, provide impor-

\section{KARGER}

E-Mail karger@karger.com

www.karger.com/ear
(C) 2013 S. Karger AG, Basel

$1022-6877 / 13 / 0203-0137 \$ 38.00 / 0$
Prof. Dr. Friedrich Martin Wurst

Department of Psychiatry and Psychotherapy II Christian Doppler Hospital, Paracelsus Medical University

Ignaz-Harrer-Strasse 79, AT-5020 Salzburg (Austria)

E-Mail f.wurst@salk.at 
tant objective information on more distant drinking status that may not be accurately obtained from the patient's verbal report or clinical examination. They are advantageous as compared to traditional biological state markers, such as liver enzymes or mean corpuscular volume, since those are indirect measures of ethanol intake. Therefore, they are limited with regard to the time period for previous drinking and/or are confounded due to age, gender, other ingested substance intake and non-alcohol-associated diseases [2-5]. On this background, direct ethanol metabolites have gained interest during the last two decades.

Ethyl glucuronide (EtG), a promising marker of alcohol intake, is a direct metabolite of alcohol formed as a conjugate of alcohol with glucuronic acid in the liver, catalyzed by the enzyme uridine diphosphate glucuronyltransferase [3, 5-7]. EtG is measureable in tissue, blood, hair, and, most commonly, in urine [6]. With an estimated 5 million or more tests conducted annually in the USA [D. Lewis, CEO, US Drug Test Lab, Chicago, 5/2/12, pers. commun.] it is the most widely used direct ethanol metabolite. EtG testing has gained widespread use because EtG: (1) is detectable in urine (still the most common matrix for testing); (2) can be detected in urine for up to 7 days; (3) testing is relatively inexpensive, and (4) it is now widely available through most reference laboratories.

Despite its growing popularity, urine EtG (UEtG) testing faces certain limitations. A positive test result can be misleading because it can be positive from extraneous exposure to alcohol from any of a myriad of products such as food [8], mouthwash [9], hand-sanitizing gels [10], or over-the-counter medications. Also, in vitro formation of EtG from bacterial action in urine in some settings $[11,12]$ or from consuming sugar and yeast [13] has been reported.

There is no universally agreed upon cutoff that accurately distinguishes between drinking and extraneous exposure. However, based on the fact that exposure studies never yielded results $>1,000 \mathrm{ng} / \mathrm{ml}$, a differential cutoff has been suggested of 1,000 ng/ml or more for EtG to confirm drinking [14]. In addition, a recent revision of the SAMHSA advisory suggests that values of between 500 and $1,000 \mathrm{ng} / \mathrm{ml}$ could be from previous drinking as well as from recent intense extraneous exposure within $24 \mathrm{~h}$ or less [15].

Given these limitations, an additional, accurate, convenient, and affordable method for monitoring alcohol use might be desirable. New devices that appear to hold promise have emerged for monitoring alcohol abstinence, including transcutaneous alcohol-monitoring devices [16-18] and, more recently, cellular photo digital breathalyzers (CPDB).
Transcutaneous alcohol-monitoring devices use fuel cells to periodically measure alcohol exuded through the skin. The results are forwarded daily to a central computer via modem where the readings are analyzed and reports are generated. Measurement of alcohol levels in this manner have been shown to accurately correlate with blood alcohol [19]. The transcutaneous devices, however, also have significant operational drawbacks because they must be securely attached to an extremity and must be worn continuously. They are therefore cumbersome, intrusive, can cause discomfort and may be stigmatizing.

A new CPDB device that is portable similar to a breathalyzer has been introduced. Results are transmitted over the cellular network along with a photo. The photo is taken of the user's face mid-exhalation when the breath alcohol is sampled. The facial image is available for visual examination to identify the donor along with the breath alcohol result immediately on a monitoring website. This new device is small and can be carried in a purse or pocket and works in conjunction with a smartphone that can be programmed to beep when a test is required. The software can be set to send an e-mail or text message to the monitor to report a positive test or if a test is missed. Additionally, if alcohol is detected, a repeat test is automatically requested $15 \mathrm{~min}$ later. This is important to eliminate extraneous exposure to alcohol vapor in the atmosphere as a cause for a positive test. Extraneous alcohol vapor, which could occur from alcohol hand sanitizer, mouthwash, etc., dissipates within a few minutes. These devices appear to be simple, affordable, accurate, and reflect real-time readings of breath alcohol, as they report immediately, and thus may be more sensitive and specific for alcohol use than other methods.

This study aims at elucidating the usability and accuracy of the CPDB as compared to self-reports in a naturalistic setting. In addition, the results were compared to random UEtG testing. The frequencies of use, 4 times daily for CPDB and weekly testing with EtG, are compared because they are practical levels of use in the field for the two methods of testing.

\section{Methods}

\section{Design}

This prospective pilot study aims at comparing CPDB, self-reports and UEtG testing for monitoring alcohol use in the same subjects over a 5 -week period. Subjects were contacted daily by phone to encourage compliance, answer questions and to notify them when to submit the urine sample. All urine specimens were collected between 9 a.m. to 1 p.m. at a designated collection site. 
Table 1. Descriptive data of the subjects

\begin{tabular}{|c|c|c|c|c|c|c|c|c|}
\hline \multirow[t]{2}{*}{ Subject } & \multirow[t]{2}{*}{$\begin{array}{l}\text { Drinking } \\
\text { episodes }\end{array}$} & \multirow{2}{*}{$\begin{array}{l}\text { Maximum number } \\
\text { of standard drinks } \\
\text { on one occasion }\end{array}$} & \multirow{2}{*}{$\begin{array}{l}\text { Number of UEtG } \\
\text { tests/number of } \\
\text { positive UEtG tests }\end{array}$} & \multirow{2}{*}{$\begin{array}{l}\text { Number of breath } \\
\text { tests/number of } \\
\text { positive breath tests }\end{array}$} & \multicolumn{2}{|c|}{$\begin{array}{l}\text { Alcohol levels for positive } \\
\text { breath tests, } \mathrm{g} / \mathrm{dl}\end{array}$} & \multicolumn{2}{|c|}{$\begin{array}{l}\text { Minutes from drink to } \\
\text { breath test }\end{array}$} \\
\hline & & & & & lowest & highest & $\min$. & $\max$. \\
\hline 1 & 7 & 3 & $5 / 0$ & $140 / 7$ & 0.007 & 0.064 & 59 & 205 \\
\hline 2 & 2 & 6 & $5 / 0$ & $134 / 2$ & 0.029 & 0.105 & 271 & 330 \\
\hline 3 & 10 & 3 & $5 / 0$ & $140 / 10$ & 0.010 & 0.320 & 42 & 255 \\
\hline 6 & 5 & 6 & $5 / 0$ & $140 / 5$ & 0.012 & 0.170 & 38 & 66 \\
\hline 7 & 7 & 4 & $4 / 0$ & $122 / 7$ & 0.015 & 0.147 & 15 & 122 \\
\hline 8 & 22 & 10 & $5 / 1$ & $127 / 22$ & 0.006 & 0.257 & 11 & 216 \\
\hline 9 & 5 & 4 & $5 / 0$ & $140 / 5$ & 0.010 & 0.104 & 62 & 139 \\
\hline 10 & 6 & 3 & $5 / 0$ & $120 / 6$ & 0.014 & 0.081 & 24 & 221 \\
\hline 11 & 2 & 2 & $3 / 0$ & $128 / 2$ & 0.011 & 0.013 & 141 & 230 \\
\hline
\end{tabular}

Simultaneously, over the same period the subjects were reminded to submit CPDB readings 4 times daily: upon arising, after lunch, after dinner, and before bedtime. Subjects were asked to keep a detailed log of their alcohol use (day, time, type of alcohol, and amount) as well as a record of all food, drink, and/or products in the environment that might contain alcohol. At the end of the study, subjects completed a questionnaire regarding acceptability and ease of providing urine and breath samples.

\section{Subjects}

Twelve subjects were recruited via a posting on Craig's List. The ad stated, 'Social drinkers sought to participate in a 5-week alcohol-monitoring study. Must be between 21 and 60 with no history of alcoholism, addictions, or current pregnancy. Upon completion subjects may keep their breathalyzer device, value $\$ 650$. To participate call <phone number $>$.' Social drinkers were defined as drinking less than 3 times per week. Subjects were screened via telephone. Of the first 15 who called, 3 individuals were eliminated because they consumed alcohol more than 3 times per week. Of the 12 selected subjects, 8 were men and 4 women, between 24 and 52 years of age. All subjects signed informed consent to participate and were anonymized. Subjects were allowed to suspend testing for 3-8 days because of holidays and vacations and these days were added to the end so that all subjects participated in monitoring for a total of 35 days.

\section{Laboratory and CPDB Testing}

MedTox Diagnostics, Inc., Burlington, N.C., USA, provided UEtG testing utilizing the Microgenics immunoassay with reflex LC/MS/MS confirmation. The cutoff for the EtG immunoassay was $500 \mathrm{ng} / \mathrm{ml}$, and is the most commonly used cutoff. The CPDB devices were provided by Soberlink, Inc., Costa Mesa, Calif., USA.

\section{Monitoring Preference}

Subjects were asked the following questions at the end of the study: (1) If you had to choose one method of monitoring over the other, would you choose random urine drug testing weekly or 4 times daily blowing in the Soberlink CPDB device? (2) Please describe the difference between both methods of monitoring.

\section{IRB Approval}

The design of this study as well as all data collection and patient protection procedures were reviewed and approved by the full membership of a duly constituted Independent Review Board, RCRC, Austin, Tex., USA.

\section{Results}

The 12 subjects reported 2-22 drinking episodes each resulting in a total of 84 drinking episodes. The maximum number of drinks per occasion ranged between 2 and 10 where 1 standard drink was defined as $14 \mathrm{~g}$ ethanol according to the NIAAA definition [20]. A total of 1,609 breath tests were performed and 55 UEtG tests were collected.

Of the breath tests, 71 were not collected by 6 subjects for various reasons, including 'forgot to test' and 'battery was dead'. The compliance rate for successful breath testing was thus $96 \%$. Of the total breath tests, 1,525 (94.8\%) were negative and $84(5.2 \%)$ were positive. On average, positive breath tests were taken approximately $2 \mathrm{~h}$ after reported drinking episodes (range 8-330 $\mathrm{min}$ ). Of a total of 84 reported drinking episodes, 83 were followed by a positive breath test resulting in a sensitivity of $98.8 \%$. In 1 case, the breath test at 9 p.m. was negative following a reported consumption of 3 beers at 6 p.m. There was 1 false-positive breath test (result $0.007 \mathrm{~g} / \mathrm{dl}$ ) that was un- 
explained. The individual number of breath tests ranged from 120 to 140 with positive test levels of between 0.006 and $0.358 \mathrm{~g} / \mathrm{dl}$.

Of 60 possible UEtG tests, 55 were obtained. Five tests were missed by 4 subjects who failed to test for various reasons, including 'forgot to go' and 'collection site closed'. The compliance rate for successful UEtG testing was thus $92 \%$. Of the 55 UEtG tests submitted, 1 (1.8\%) was positive and $98.2 \%$ were negative. The positive test was obtained the morning after the subject reported having 5 drinks. There were no false-positive UEtG tests (for further details, see table 1).

Regarding the monitoring preference questions, all participants preferred the CPDB device. Differences mentioned between the two methods of monitoring were the following: 'It's much easier to take $30 \mathrm{~s} 4$ times per day than to drive to a collection site and wait sometimes $1 / 2$ hour to submit a urine sample.' 'Much more convenient to blow in the Soberlink from home than to go to a collection site.' 'Embarrassing to submit a urine. Easy to blow in Soberlink device.' 'Much prefer blowing in Soberlink device.' 'No comparison. Prefer blowing.' 'Just easier.' 'More trouble to drive somewhere and wait to give urine sample.' ' 1 min per breath test, $30-45$ min per urine.' 'No comparison.'

\section{Discussion}

The major findings of this pilot study employing the portable CPDB using data transmission over a cellular network along with a photo are: (1) of all reported drinking episodes, $98.8 \%$ were detected by the CPDB. (2) The compliance rate for successful breath testing was with 96\% extraordinarily high. (3) All participants preferred the CPDB over the EtG testing. These findings are of importance since alcohol is one of the most common substances of abuse.

UEtG testing has emerged over the past decade and has gained widespread use in monitoring; however, it also faces certain limitations. These include the fact that only a higher dose of ethanol results in detectable UEtG values for longer than $24 \mathrm{~h}$ : Wojcik and Hawthorne [21] found UEtG to be positive at $24 \mathrm{~h}$ in 5 out of 6 cases with doses of $0.39-0.85 \mathrm{~g}$ ethanol $/ \mathrm{kg}$ body weight and 0 of 2 with doses of $0.19-0.28 \mathrm{~g}$ ethanol $/ \mathrm{kg}$ body weight at a cutoff of $100 \mathrm{ng} / \mathrm{ml}$. Halter et al. [11] found 4 out of 13 subjects to be UEtG-positive for more than $44 \mathrm{~h}$ after an ethanol intake of $0.5-0.8 \mathrm{~g}$ ethanol $/ \mathrm{kg}$ body weight. Also in this study a low cutoff was chosen with a limit of quantitation of $0.45 \mu \mathrm{mol} / \mathrm{l}$. Since in our study the commonly used cutoff of $500 \mathrm{ng} / \mathrm{ml}$ was used, it cannot be excluded that some positives in the range of $100-500 \mathrm{ng} / \mathrm{ml}$ were missed. The SAMHSA advisory of 2012 on 'The Role of Biomarkers in the Treatment of Alcohol Use Disorders' [15] states: A 'very low' positive (100-500 ng/ml) may indicate: previous heavy drinking (1-3 days), previous light drinking (12-36 h) or recent 'extraneous' exposure. Therefore, to monitor for total abstinence, the cutoff of $100 \mathrm{ng} / \mathrm{ml}$ has been suggested $[14,15]$.

If some drinking is not detected using the common UEtG cutoff, it can encourage subjects to continue to drink and presents problems for agencies that rely on the tests for detection of drinking and assurance of abstinence. Furthermore, if tests are falsely positive, it causes false accusations and can lead to unjustified sanctions, such as loss of visitation or loss of medical license. Therefore, a complementary and/or additional accurate and reliable method of monitoring alcohol is desirable.

Our data suggest that the real-time use of a breathalyzer such as a CPDB device could be such a solution. The finding that EtG in urine is detectable in social drinkers with single drinking episodes only in few cases for more than $24 \mathrm{~h}$ after doses of $0.5-0.8 \mathrm{~g}$ ethanol $/ \mathrm{kg}$ body weight are in line with previous studies $[11,21]$.

Transdermal alcohol sensors are another method established, studied, and validated in the last years as an effective and feasible method for measuring the transdermal alcohol concentration [16]. One device, the Secure Continuous Remote Alcohol Monitoring (SCRAM) bracelet, has been evaluated in controlled laboratory environments and field studies [18] and furthermore has been found to be effective for the reduction of alcohol intake in the context of contingency management [17]. However, embarrassment, experiencing negative attention, marks on skin, interference with physical activity, discomfort [17] about the bracelet and water accumulation over time [22] had been reported. Those may limit the utility of transdermal devices.

The CPDB is an unobtrusive, easy-to-use device. As the data are transmitted via the cellular network, the participants do not have to go to site for a breath test. Therefore, it is not time-consuming, no staff is directly involved and an immediate feedback can be given. Also, participants may have the opportunity to gain new levels of insight regarding their alcohol consumption. Therefore, CPDB cannot only be used as a monitoring instrument but also as a therapeutic method, alone or in the context of already existing therapeutic approaches such as contingency management. 
The retail price of the Soberlink device is USD 650 plus USD 150 per month for monitoring. The annualized cost of monitoring using the CPDB would therefore be USD 2,450 per person. However, the price remains the same no matter how many times the device is used. On the background of the recent price reduction the annual costs would be now USD 2,020. In comparison, usual costs for UEtG testing in the USA range between 15 and 30 USD. Aiming at a good balance between practicability, reliability and security, random UEtG testing on average every 3 days would result in annual costs of between USD 1,500 and 3,000. If constant monitoring employing UEtG is desirable, daily testing would be required and result in annual costs of approximately USD 4,500-9,000. However, in the case of daily urine testing, practicability is questioned.

\section{Limitations}

The study design aimed at elucidating the usability of CPDB. Therefore, the time points for breath tests were given and known by the participants. This would in the context of monitoring be a severe limitation since subjects can attempt to avoid detection of drinking episodes by timing their drinking. To overcome this, random testing is required. It is quite likely that the very good compliance is at least in part due to the daily telephone calls. Contacting subjects daily by phone might even be feasible in routine settings or also could be done by automated text messages. Finally, the fact that participants could keep their breathalyzer device at the end of the study might have impacted the acceptability outcome.

\section{Conclusion}

The data suggest that the CPDB device holds promise in detecting not only high but also moderate and low alcohol intake. Furthermore, it seems to have advantages as compared to biomarker tests and other monitoring devices. The preference for CPDB by the participants might explain the high compliance. Further research involving a larger number of subjects, longer test periods, different subject populations (e.g. individuals in recovery or in court-ordered monitoring programs), and comparison with biomarkers and transdermal devices are needed.

\section{Acknowledgement}

Soberlink, Inc. contributed 12 free Soberlink Devices and Meditox contributed 55 free EtG tests.

\section{Disclosure Statement}

The authors have no conflicts of interest to disclose.

\section{References}

1 McLellan AT, Skipper GE, Campbell M, DuPont RL: Five-year outcomes in a cohort study of physicians treated for substance use disorders in the United States. BMJ 2008; 337:a2038.

2 Allen JP, Marques P, Wurst FM: Biomarkers of alcohol use: their nature, strengths and limitations. Mil Med 2009;173:v-viii.

3 Helander A: Biological markers in alcoholism. J Neural Transm 2003; 66(suppl):15-32.

4 Litten RZ, Bradley AM, Moss HB: Alcohol biomarkers in applied settings: recent advances and future research opportunities. Alcohol Clin Exp Res 2010;34:955-967.

5 Walsham NE, Sherwood RA: Ethyl glucuronide. Ann Clin Biochem 2012;49:110-117.

6 Wurst FM, Metzger JW, on behalf of the WHO/ISBRA study on biological state and trait markers of alcohol use and dependence: The direct ethanol metabolite Ethyl glucuronide is a useful marker of recent alcohol consumption. Alcohol Clin Exp Res 2002;26: 1114-1119.
7 Wurst FM, Vogel R, Jachau K, Varga A, Alling C, Alt A, Skipper GE: Ethyl glucuronide discloses recent covert alcohol use not detected by standard testing in forensic psychiatric inpatients. Alcohol Clin Exp Res 2003;27:471476.

8 Musshoff F, Albermann E, Madea B: Ethyl gluduronide and ethyl sulfate in urine after consumption of various beverages and foods - misleading results? Int J Legal Med 2010; 124:623-630.

-9 Costantino A, DiGregorio EJ, Korn W: The effect of incidental alcohol exposure due to the use of mouthwash on ethylglucuronide concentrations in urine. Ther Drug Monit 2005;27:215.

10 Rohrig T, Huber C, Goodson L, Ross W: Detection of ethylglucuronide in urine following the application of Germ-X. J Anal Toxicol 2006;30:703-704.
11 Halter CC, Dresen S, Auwaerter V, Wurst FM, Weinmann W: Kinetics in serum and urinary excretion of ethyl sulfate and ethyl glucuronide after medium dose ethanol intake. Int J Legal Med 2008;122:123-128.

12 Helander A, Olsson I, Dahl H: Postcollection synthesis of ethyl glucuronide by bacteria in urine may cause false identification of alcohol consumption. Clin Chem 2007;53:18551857.

13 Thierauf A, Wohlfarth A, Auwaerter V, Perdekamp MG, Wurst FM, Weinmann W: Urine tested positive for ethyl glucuronide and ethyl sulfate after consumption of yeast and sugar. Forensic Sci Int 2010;202:e45-e47.

14 Thierauf A, Halter CC, Rana S, Auwärter V, Wohlfarth A, Wurst FM, Weinmann W: Urine tested positive for ethyl glucuronide after trace amounts of ethanol. Addiction 2009; 104:2007-2012. 
15 US Department of Health and Human Services (2006) Substance Abuse and Mental Health Services Administration (SAMHSA), Center for Substance Abuse Treatment. The role of biomarkers in the treatment of alcohol disorders. Substance Abuse Treatment Advisory 5:1-8. http://www.kap.samhsa. gov/products/manuals/advisory/pdfs/0609_ biomarkers.pdf (accessed November 6, 2012).

16 Hawthorne JS, Wojcik MH: Transdermal alcohol measurement: a review of the literature. Can Soc Forensic Sci J 2006;2:65-71.
Barnett NP, Tidey J, Murphy JG, Swift R, Colby SM: Contingency management for alcohol use reduction: a pilot study using transdermal alcohol sensor. Drug Alcohol Depend 2011; 118:391-399.

18 Sakai JT, Mikulich-Gilbertson SK, Long RJ, Crowley TJ: Validity of transdermal alcohol monitoring: fixed and self-regulated dosing. Alcohol Clin Exp Res 2006;30:26-33.

19 Marques PR, McKnight AS: Evaluating Transdermal Alcohol Measuring Devices. National Highway Traffic Safety Administration 2007.
20 National Institute on Alcohol Abuse and Alcoholism (NIAAA), 2005: A pocket guide alcohol screening and brief intervention. Available at http://pubs.niaaa.nih.gov/publications/Practitioner/pocketguide/pocket_ guide2.htm (accessed May 24, 2013).

21 Wojcik MH, Hawthorne JS: Sensitivity of commercial ethyl glucuronide (EtG) testing in screening for alcohol abstinence. Alcohol Alcohol 2007;42:317-320.

22 Marques PR, McKnight AS: Field and laboratory alcohol detection with two types of transdermal devices. Alcohol Clin Exp Res 2009; 33:703-711. 